\title{
Plasma modification of microporous polymer membranes for application in biomimetic dissolution studies
}

\author{
Michael M. Puppolo ${ }^{1,2^{*}}$, Justin R. Hughey ${ }^{3}$, Bruce Weber ${ }^{1}$, Traciann Dillon ${ }^{1}$, David Storey ${ }^{1}$, Elizabeth Cerkez ${ }^{2}$ \\ and Susan Jansen-Varnum ${ }^{2}$
}

\begin{abstract}
Biorelevant dissolution is an indispensable tool utilized during formulation development and optimization for the prediction of in vivo bioavailability of pharmaceutical agents. Within that framework, membrane-permeation dissolution methodologies are widely used to model drug absorption. The current work evaluates polymer membrane surface modifications for production of biomimetic membranes to be employed in biorelevant dissolution studies. Biomimetic membranes exhibit hydrophilic and hydrophobic properties to simulate the intestinal membrane environment. Low temperature plasma treatment of microporous polyethersulfone (PES), nylon and polypropylene (PP) polymer membranes was applied to produce low energy surface layers with permanent hydrophobic and hydrophilic functionalities. Surface modifications on microporous polymer membranes were achieved by plasma treatments using tetrafluoromethane $\left(\mathrm{CF}_{4}\right)$, perfluorohexane $\left(\mathrm{C}_{6} \mathrm{~F}_{14}\right)$, dichloromethane (DCM) and water $\left(\mathrm{H}_{2} \mathrm{O}\right)$. Surface characterization of treated membranes was evaluated using scanning electron microscopy energy dispersive $x$-ray spectroscopy (SEM-EDS), water contact angle (CA) and x-ray photoelectron spectroscopy (XPS) techniques. SEM-EDS analysis of polymer membranes treated with fluorinated and chlorinated solvents/gases depicts altered surface morphologies with enriched porosity. SEM-EDS and XPS analyses demonstrate the chemical modification at the surface of treated membranes is strongly influenced by the type of treatment gas or solvent. Results show fluorination as a more effective and less destructive treatment technique. XPS confirmed the presence of elemental fluorine functional groups at the surface of the PES and nylon membranes. Evaluating elemental changes ( $\mathrm{F} / \mathrm{C}$ ratio) from multiple techniques confirms fluorinated plasma treatments are localized to the surface of the membrane and do not significantly affect the bulk properties. In a supplemental study, a detailed comparison of the plasma treated polymer membranes and porcine intestines revealed the biomimetic nature of the modified membranes.
\end{abstract}

Keywords: Plasma cleaner, Hydrophobic treatment, Biomimetic membranes, Membrane-permeation dissolution, Unstirred aqueous layer, Surface modifications, Plasma treatment

\section{Background}

The most popular mode of drug administration is the oral route, denoting the gastrointestinal tract (GIT) as the primary site for drug delivery (York 2013; Rowland 1972; Maisel et al. 2015). Of the anatomical structures comprising the GIT, the small intestine presents the

\footnotetext{
* Correspondence: mpuppolo@hovione.com

${ }^{1}$ Hovione LLC, 40 Lake Drive, East Windsor, NJ 08520, USA

2Department of Chemistry, Temple University, 1901 North 13th Street,

Philadelphia, PA 19122, USA

Full list of author information is available at the end of the article
}

largest surface area $\left(\sim 30 \mathrm{~m}^{2}\right)$, designating it as a primary site for drug absorption (Artursson and Knight 2015; Helander and Fändriks 2014). Predicting drug absorption and oral bioavailability is a critical aspect of drug development, which can be challenging due to the complexity of the human intestinal membrane. The small intestine is composed of a porous lipid membrane. Collections of villi project from the lining of intestinal epithelial cells and expose tiny hair-like microvilli to the intestinal environment. At the outermost surface, striated layers of microvilli constitute the brush border 
membrane. Adjacent to the apical brush border surface, a stagnant layer of aqueous media (unstirred aqueous layer) separates the membrane from the bulk fluid phase and is known to act as a barrier to diffusion (Porter et al. 2007). With advances in technology, fabrication of the aforementioned properties into a surrogate biological membrane has become possible (van de Waterbeemd 2000).

Biomimetic membranes embody essential chemical, physical and topographical properties such as hydrophilicity (unstirred aqueous layer, wettability of membrane from intestinal fluid), hydrophobicity (lipophilicity of the brush border membrane), porosity (neighboring epithelial cells, intestinal crypts/glands in villus) and self-assembly (spontaneous organization of molecules). Biological elements can be incorporated into various scaffolds that generate biomimetic membranes, i.e. - PAMPA membranes and Caco-2 cells, but such membranes have drawbacks including inadequate stability, lengthy manufacturing times ( $>20$ days) and extensive production costs (Ruell 2003; Artursson et al. 2001; Kansy et al. 1998; Macheras et al. 2013). In contrast, novel approaches such as plasma treatment of microporous polymer membranes have been utilized for the production of biomimetic membranes (Obeso et al. 2013). An array of plasma treatment approaches (hydrophobic and hydrophilic) can be exploited to manipulate the surface of polymer membranes for a variety of applications.

Polymer materials have been adopted as an important tool in separation technologies, with numerous scientific and practical applications in a variety of including biopharmaceutics and biomimetic dissolution testing (Ho et al. 2000; Robeson 1999; Krause et al. 2003; Baker 2002; Fakhru'l-Razi et al. 2009; Shannon et al. 2008; Azarmi et al. 2007). As a classical approach to modifying the properties of polymers, wet chemical modifications have been shown to induce the presence of reactive functional groups at the surface of polymer membranes (Liston et al. 1994). However, challenges associated with overexposure to treatment conditions can lead to chemical degradation, which often limits reproducibility of the surface functionalization and stability of the modified polymer membrane (Penn and Wang 1994). To reduce the expenditure of hazardous organic solvents and enhance control over the chemical modification, solvent-free techniques have emerged as a dominant trend in the field of surface engineering research (Desmet et al. 2009). Plasma treatments are a prevailing vanguard of solventfree surface modification practices. Applicable to a wide variety of materials, plasma treatments concentrate hydrophobic and hydrophilic modifications to the surface of a polymer membrane without affecting the bulk membrane properties.

The effect of plasma-polymer interactions on the surface of treated polymer material is explained by four principle mechanisms: 1 - cleaning, 2 - ablation or etching, 3 - crosslinking and 4 - chemical structure modification (Strobel et al. 1994). Factors such as polymer chemistry, gas chemistry, reactor design and process conditions influence the results of plasma treatment (Liston 1989). Plasma processing with non-film forming gases (i.e. - oxygen, hydrogen, carbon dioxide, nitrogen and ammonia) has been utilized for hydrophilic treatments by incorporating polar functional groups at the surface of a polymer membrane (Bryjak et al. 2002; Wavhal and Fisher 2005; Kim et al. 2002). When combined with an inert gas, non-film forming gases dissociate weak surface bonds by ion bombardment and free radical reactions to produce various oxygen, amine and amide containing functional groups at the membrane surface (Cheng 2011). Polymer membranes treated by non-film forming gas plasmas would illustrate altered chemical activity and surface characteristics such as wettability and adhesion. In contrast, plasma processing with film forming gases $\left(\mathrm{CF}_{4}, \mathrm{SF}_{6}\right.$ and $\left.\mathrm{C}_{4} \mathrm{~F}_{8}\right)$ has been employed for hydrophobic treatments of polymer membranes (Gomathi et al. 2008; Selli et al. 2001; Booth et al. 1999). The polymerizing ability of such gases is conducive to deposition applications at the surface of polymer membranes. Under appropriate conditions, chain growth is propagated in the gas phase due to the abundance of reactive free radicals present during plasma formation. Gas phase polymer chains are then deposited onto the polymer surface at activated sites. In addition to polymerization of the process gas, polymerization can also occur at the surface of the membrane. Following deposition of fragmented monomers to the activated membrane surface, subsequent chain growth can occur by surface reactions with additional fragments present in the plasma (Cheng 2011). The ability to design a process tailored to introduce select physical and chemical characteristics (functional groups and physical properties) onto the surface of a membrane while maintaining the bulk polymer properties, demonstrates the versatility of plasma treatments.

Presented here is a research investigation of a unique approach to the preparation of biomimetic membranes. Although a number of applications exist for plasma treated microporous polymer membranes, they have not been extensively studied as a platform for biomimetic membranes in dissolution testing. Plasma modifications can be manipulated to produce biomimetic polymer membranes that act as a surrogate for the intestinal membrane, thus tailoring their application for dissolution testing (Puppolo et al. 2017). A schematic showing the biomimetic membranes in an experimental permeation/ dissolution chamber that exploits the amphipathic nature of the membrane is presented in Fig. 1. In this study, hydrophobic $\left(\mathrm{CF}_{4}, \mathrm{C}_{6} \mathrm{~F}_{14}\right.$ and $\left.\mathrm{DCM}\right)$ and hydrophilic 


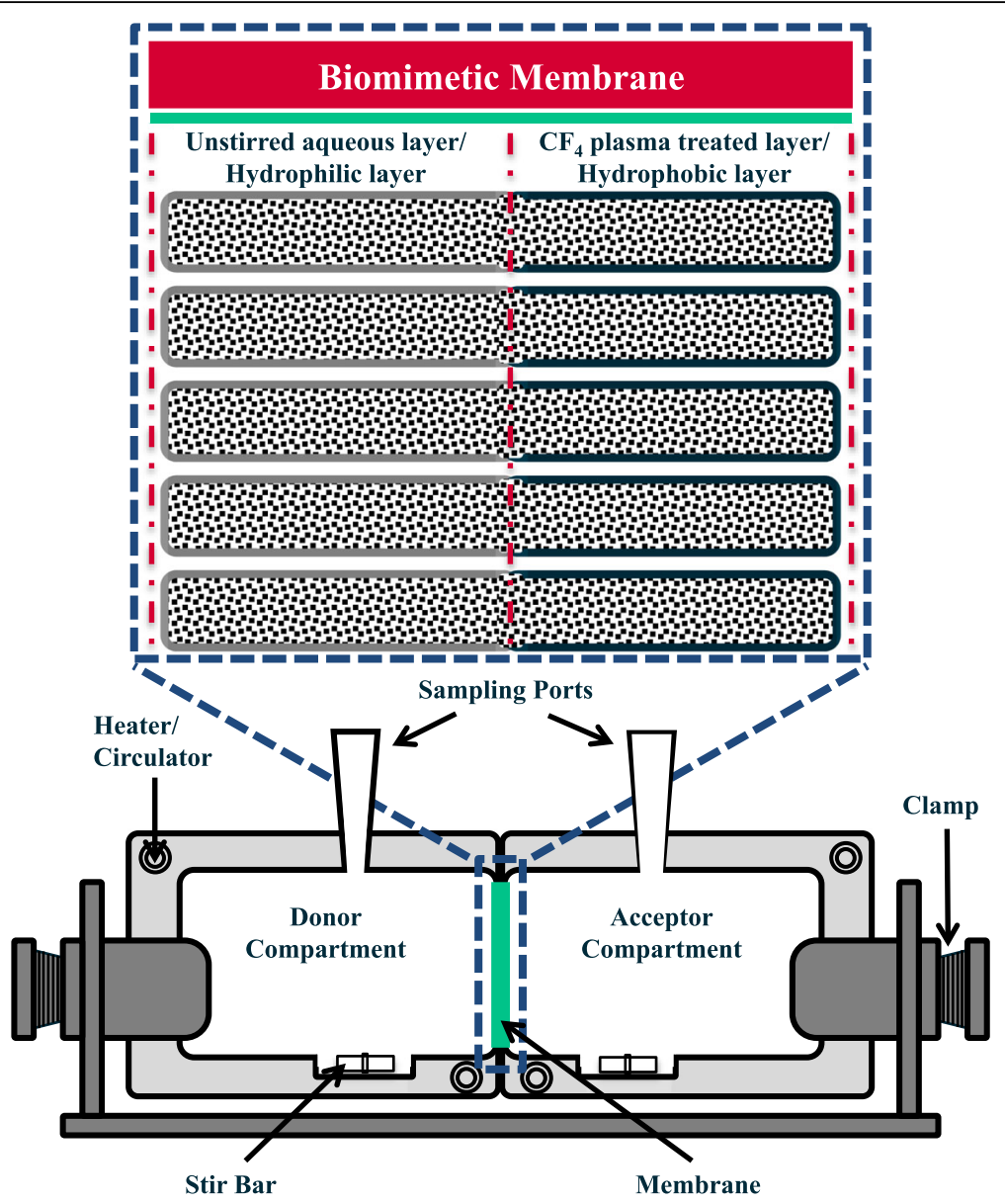

Fig. 1 Schematic illustration of a biomimetic membrane and the membrane-permeation dissolution apparatus

$\left(\mathrm{H}_{2} \mathrm{O}\right)$ plasma treatments were screened for surface modifying capabilities with hydrophilic (PES and nylon) and hydrophobic (PP) polymer membrane systems respectively. The surface properties of modified membranes were characterized by water contact angle (CA) testing, X-ray photoelectron spectroscopy (XPS) and scanning electron microscopy with energy dispersive Xray spectroscopy (SEM-EDS) analytical techniques to evaluate the extent of treatment, membrane morphology and chemical composition of the membrane surfaces.

\section{Methods}

\section{Materials}

Polyethersulfone (diameter $-25 \mathrm{~mm}$, pore size $-0.03 \mu \mathrm{m}$, $0.2 \mu \mathrm{m}$ and $0.45 \mu \mathrm{m}$, nominal thickness $-110 \mu \mathrm{m}$ to $150 \mu \mathrm{m}$ ), nylon (diameter $-25 \mathrm{~mm}$, pore size $-0.1 \mu \mathrm{m}$, $0.2 \mu \mathrm{m}$ and $0.45 \mu \mathrm{m}$, nominal thickness $-65 \mu \mathrm{m}$ to $125 \mu \mathrm{m}$ ) and polypropylene (diameter $-25 \mathrm{~mm}$, pore size $-0.22 \mu \mathrm{m}$ and $0.45 \mu \mathrm{m}$, nominal thickness $110 \mu \mathrm{m})$ polymer membrane filters were purchased from Sterlitech Corporation (Washington, USA). All
ACS or reagent grade solvents (dichloromethane and methanol) and perfluorohexane $(98+\%$ purity) were obtained from VWR (New Jersey, USA). Commercial grade tetrafluoromethane (99.2\% purity) gas was purchased from Concorde Specialty Gases (New Jersey, USA). Ultrapure water $(18 \mathrm{M} \Omega \cdot \mathrm{cm})$ was obtained from a Milli- $Q^{\circ}$ purification system (EMD Millipore, New Jersey, USA).

\section{Membrane modification \\ Plasma treatment}

A PDC-32G inductively coupled plasma cleaner equipped with a PDC-32Q quartz chamber and PDC-32 T sample tray was kindly loaned from Harrick Plasma (New York, USA) for hydrophobic and hydrophilic plasma treatments of polymer membranes. This apparatus uses a $13.56 \mathrm{MHz}$ radio frequency signal to generate the plasma. Membranes were positioned on the quartz sample tray and secured by a polytetrafluoroethylene membrane holder. The system was purged with nitrogen gas and evacuated by vacuum to a base pressure of $\sim 500 \mathrm{mTorr}$ for $5 \mathrm{~min}$ to remove any volatilized degradation products and saturate the 
chamber with water vapor. For the hydrophilic treatments of PP membranes, $\mathrm{H}_{2} \mathrm{O}$ was introduced as a liquid via a gas tight syringe and evaporated at a rate controlled by the pressure of the system ( $100 \mathrm{mTorr})$. For the hydrophobic treatments of PES and nylon membranes, process gas $\left(\mathrm{CF}_{4}\right)$ was introduced to the chamber at a rate of $10 \mathrm{psi}$ through a three-way needle valve, process solvents (DCM, $\mathrm{C}_{6} \mathrm{~F}_{14}$ ) were introduced as a liquid via a gas tight syringe and evaporated at a rate controlled by the pressure of the system ( 100 mTorr). Following equilibration of the plasma chamber, the glow discharge was initiated at $18 \mathrm{~W}$ for various treatment times $(1-5 \mathrm{~min})$. For PES membranes a 30-min treatment was evaluated for completeness. To ensure plasma uniformity, the chamber pressure was maintained at $\sim 500 \mathrm{mTorr}$. Upon completion of the plasma treatment, the RF generator was switched off and the chamber was evacuated for $5 \mathrm{~min}$ before venting to atmospheric pressure.

\section{Membrane characterization Water contact angle}

To quantify the wettability of membranes, water contact angle analyses of unprocessed and plasma treated polymer membranes were performed on a static contact angle apparatus (Hovione LLC, New Jersey, USA). A sessile drop was formed by dispensing $50 \mu \mathrm{L}$ of ultrapure water through a gas tight syringe onto the horizontal membrane surface. The drop was stabilized on the membrane surface for $5 \mathrm{~s}$ to reach static state and an image of was captured. Contact angles were measured from the images. Analyses were performed in triplicate.

\section{Scanning electron microscopy (SEM)}

A FEI Quanta 450 FEG environmental scanning electron microscope (FEI, USA) equipped with a X-Max silicon drift energy dispersive $\mathrm{x}$-ray detector (Oxford Instruments, UK) was used to characterize the surface morphology and elemental composition of unprocessed and plasma treated polymer membranes. Analyses were performed under low vacuum with an applied acceleration voltage of $10 \mathrm{kV}$. SEM images were obtained using a secondary electron

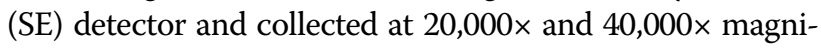
fications. Elemental analysis of polymer membrane cross sections was performed using an energy dispersive $\mathrm{x}$ ray spectrometer and analyzed with Aztec 2.1 software (Oxford Instruments, UK).

\section{$X$-ray photoelectron spectroscopy (XPS)}

The chemical composition of membrane surfaces was determined by using a VG Scientific XPS with a Mg Ka $\mathrm{X}$-ray source operating at $280 \mathrm{~W}, 15 \mathrm{kV} \times 25 \mathrm{~mA}$. Pass energy of $50 \mathrm{eV}$ was used for all spectra. Samples of unprocessed and processed polymer membranes were prepared by securing the membrane to the sample holder with copper tape. All data was analyzed using CasaXPS software. The C $1 \mathrm{~s}$ peak was used to eliminate static charging effects. Atomic ratios were normalized using known cross sections as describe in the published work of Wagner et al. (1981). Elements were identified by their strongest binding energy regions: $\mathrm{C} 1 \mathrm{~s}(287 \mathrm{eV}), \mathrm{O} 1 \mathrm{~s}(531 \mathrm{eV}), \mathrm{S} 2 \mathrm{p}$ $(165 \mathrm{eV}), \mathrm{N} 1 \mathrm{~s}(402 \mathrm{eV})$ and F 2p $(710 \mathrm{eV})$.

\section{In vitro membrane-permeation dissolution}

A description of the dissolution procedure can be seen in Puppolo et al. (2017).

\section{Results and discussion \\ Membrane treatment \\ Water vapor plasma treatment of polypropylene membranes}

To engineer a membrane with asymmetric surface properties, water vapor plasma treatments were performed to enhance the wettability of a hydrophobic polypropylene membrane. The surface state of treated polypropylene membranes was characterized using water contact angle measurements to assess the efficiency of the water vapor plasma treatment (Table 1). Treated polypropylene membranes exhibited improved wettability and were visually equivalent to unprocessed membranes by microscopy. Triplicate analysis of treated polypropylene membranes indicated the hydrophilic surface functionalization groups were removed following exposure to water during initial testing. The initial increased wettability of the membranes may be attributed to hydrophilic species existing in the pores of the membrane, which are subsequently absorbed into the bulk water during the first contact angle measurement. Due to the limited stability of the surface modification on treated membranes, the water vapor plasma treatment was not investigated for application in a membrane-permeation dissolution apparatus/method.

\section{Dichloromethane plasma treatment of polyethersulfone and nylon membranes}

Chlorinated plasmas have been employed for hydrophilic modifications of saturated hydrocarbon polymers, such as polypropylene, to increase membrane wettability. (Upadhyay and Bhat 2003; Strobel et al. 1985). In addition to hydrophilic treatments, studies also suggest the application of chlorinated plasmas for hydrophobic modifications through the deposition of polymerized chlorinated films or hydrogen atom replacement (Hubert et al. 2013). To tailor the surface of polymer membranes to exhibit amphipathic properties, DCM plasma treatment of hydrophilic PES and nylon membranes was executed to decrease the apical surface wettability.

Treated PES and nylon membranes demonstrated decreased wettability (increased hydrophobicity) compared 
Table 1 Contact angle of unprocessed and plasma treated membranes $(n=3)$

\begin{tabular}{|c|c|c|c|c|}
\hline Membrane & Pore size $(\mu \mathrm{m})$ & Plasma treatment & Contact angle $(\theta)$ & Standard deviation \\
\hline Polypropylene & 0.22 & None & $105^{\circ}$ & 3 \\
\hline PES & 0.10 & None & $0^{\circ}, 40^{\circ \mathrm{a}}$ & $0,2^{\mathrm{a}}$ \\
\hline PES & 0.20 & None & $0^{\circ}, 40^{\circ a}$ & $0,2^{\mathrm{a}}$ \\
\hline Nylon & 0.10 & None & $0^{\circ}$ & 0 \\
\hline Nylon & 0.20 & None & $0^{\circ}$ & 0 \\
\hline Polypropylene & 0.22 & Water & $78^{\circ}$ & 4 \\
\hline PES & 0.10 & $\mathrm{CF}_{4}$ & $125^{\circ}, 125^{\circ \mathrm{a}}$ & $3,3^{\mathrm{a}}$ \\
\hline PES & 0.20 & $\mathrm{C}_{6} \mathrm{~F}_{14}$ & $110^{\circ}, 110^{\circ \mathrm{a}}$ & $3,3^{\mathrm{a}}$ \\
\hline PES & 0.20 & DCM & $95^{\circ}, 95^{\circ \mathrm{a}}$ & $2,2^{\mathrm{a}}$ \\
\hline Nylon & 0.10 & $\mathrm{CF}_{4}$ & $135^{\circ}$ & 2 \\
\hline Nylon & 0.20 & $\mathrm{C}_{6} \mathrm{~F}_{14}$ & $120^{\circ}$ & 3 \\
\hline Nylon & 0.20 & DCM & $116^{\circ}$ & 4 \\
\hline
\end{tabular}

${ }^{a}$ The manufacturing process imparts asymmetric pore structure on PES membranes such that the largest pores occur on one surface of the membrane and the smallest pore openings occur on the other surface. Therefore, each surfaces can be expected to have differing properties. As a result, the water contact angle was evaluated on each surface of PES membranes to ensure treatments were consistent. Nylon and PP membranes have symmetric surface properties and the two surfaces are not distinguishable from one another

to unprocessed membranes. Water contact angles of unprocessed and processed PES and nylon membranes is shown in Table 1. Sessile drop results demonstrate a significant enhancement of the water contact angle (PES: $0^{\circ}$ to $95^{\circ}$ and nylon: $0^{\circ}$ to $115^{\circ}$ ) at the surface of treated membranes. The non-plasma exposed surface of chlorinated PES and nylon membranes (data not shown) displayed contact angle measurements identical to that of unprocessed membranes $\left(0^{\circ}\right)$, thereby producing treated membranes possessing amphipathic properties, i.e. a hydrophobic side and a hydrophilic side.

SEM was used to characterize the surface morphology and atomic composition of unprocessed and chlorinated PES and nylon membranes. Although the surface transformation of unprocessed and chlorinated nylon membranes was difficult to detect by SEM analysis, images of unprocessed and DCM plasma treated PES membranes displayed a distinct surface restructuring (Fig. 2). An evaluation of unprocessed and chlorinated PES membrane surface images exemplifies a significant decrease in porosity, suggesting surface polymer crosslinking or thin film deposition (Fig. 2). In conjunction with the crosslinking of polymer chains, the deposition phenomenon can be explained by the polymerization of the DCM process gas, either on the surface of the polymer membrane or in the gaseous plasma (Zhao et al. 2013). Such interactions have been cited for fluorinated plasmas that utilized a low discharge power (Yasuda 1978).

The elemental proportions of PES membranes were examined with SEM - EDS to identify the presence of chlorine on the membranes surface (Table 2). The elemental ratios conveyed in Table 2 allude to polymer ablation and surface activation plasma modification mechanisms. A significant reduction of the oxygen/carbon $(\mathrm{O} / \mathrm{C})$ ratio $(0.19 \rightarrow 0.10)$ inferred ablation of the oxygen atoms is associated with (a) the sulfonyl functional group or (b)
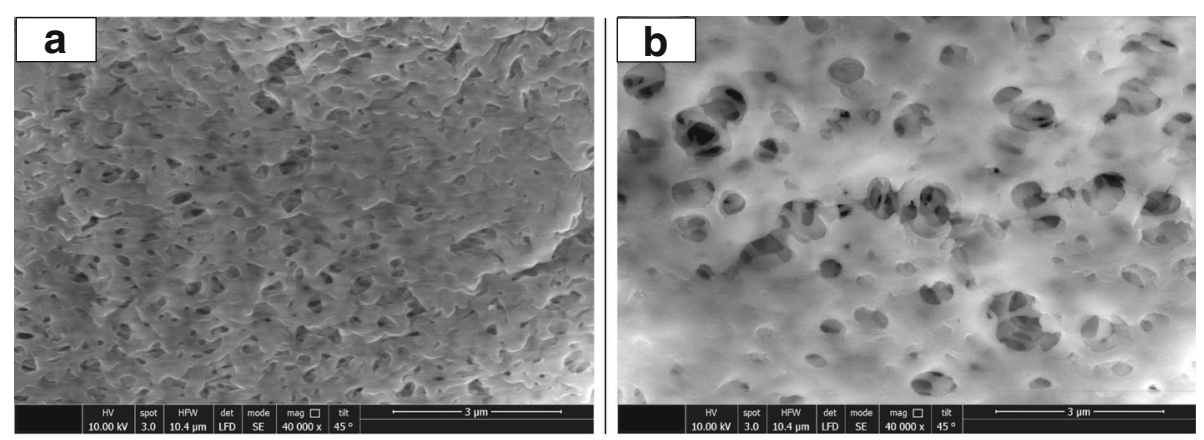

Fig. 2 SEM images at 40,000× of (a) untreated PES membranes and (b) DCM plasma treated PES membranes 
Table 2 Summary of elemental modifications on PES membranes after DCM plasma treatment $(n=1)$

\begin{tabular}{llllllll}
\hline & \multicolumn{7}{l}{ Elemental ratio (\%) } \\
\cline { 2 - 8 } Sample & $\mathrm{C}$ & $\mathrm{O}$ & $\mathrm{S}$ & $\mathrm{Cl}$ & $\mathrm{O} / \mathrm{C}$ & $\mathrm{S} / \mathrm{C}$ & $\mathrm{Cl} / \mathrm{C}$ \\
\hline PES Theoretical & 75 & 19 & 6 & 0 & 0.25 & 0.08 & 0.00 \\
PES Unprocessed & 80 & 15 & 5 & 0 & 0.19 & 0.06 & 0.00 \\
PES DCM Treated & 67 & 7 & 23 & 3 & 0.10 & 0.34 & 0.04 \\
\hline
\end{tabular}

Elemental ratio excludes hydrogen contributions

scission of the ether linkage. Concurrent with ablation, chlorinated species may attach at sites where free radicals are present. Plasma discharge of DCM generates chlorinated methyl radicals and chlorine radicals in addition to other chlorinated moieties (Eqs. 1-3) (Martinez et al. 2012).

$$
\begin{aligned}
& e+\mathrm{CH}_{2} \mathrm{Cl}_{2} \rightarrow \cdot \mathrm{CH}_{2} \mathrm{Cl}+\cdot \mathrm{Cl} \\
& \mathrm{CH}_{2} \mathrm{Cl}_{2}+\cdot \mathrm{Cl} \rightarrow \cdot \mathrm{CHCl}_{2}+\mathrm{HCl} \\
& \cdot \mathrm{CH}_{2} \mathrm{Cl}+\cdot \mathrm{CH}_{2} \mathrm{Cl} \rightarrow \mathrm{ClCH}_{2}-\mathrm{CH}_{2} \mathrm{Cl}
\end{aligned}
$$

\section{Perfluorohexane plasma treatment of polyethersulfone and nylon membranes}

Fluorocarbon plasmas promote two treatment mechanisms: 1 - fluorination and 2 - polymerization, each of which is contingent on the fluorine/carbon ratio of the process gas/solvent. A plasma gas discharge with a large fluorine/carbon ratio (> 3) will induce fluorination rather than polymerization (Coburn and Winters 1979). Deposition and/or polymerization of plasma moieties to polymer membranes can be used to introduce a variety of $\left(\mathrm{CF}_{2}\right)_{\mathrm{n}}$ polymer units to the surface and enhance the biomimetic nature of the membrane. Perfluorohexane plasma treatment of PES and nylon membranes was performed to generate hydrophobic surfaces. Water contact angles of unprocessed and perfluorohexane plasma treated PES and nylon membranes can be seen in Table 1. Sessile drop results portray an enhanced water contact angle (PES: $0^{\circ}$ to $110^{\circ}$ and nylon: $0^{\circ}$ to $120^{\circ}$ ) at the surface of treated membranes. Relative to PES, nylon membranes appear more susceptible to fluorination by perfluorohexane plasma. This suggests the removal of hydrogen atoms from saturated carbons on the polymer backbone by fluorinated radical species.

Perfluorohexane plasma treated PES and nylon membranes were characterized by SEM (Fig. 3). Compared to unprocessed membranes, fluorinated membranes showed surface morphology changes such as enhanced porosity and rigidity. Increased surface rigidity is implied by the enhanced surface density of the polymer chains as evidenced by the decreased pore size of treated membranes, as well as the implied barriers to translation motion of the polymer chains related to the greater steric bulk of fluorine atoms as compared to hydrogen atoms. No direct quantitative measurement of rigidity was performed in this study; instead, increased rigidity was inferred from SEM images and theoretical considerations. The most ostensible explanation regarding membrane pore size reduction is cross-linking and/or polymerization. Due to a small fluorine/carbon ratio $(<3), \mathrm{C}_{6} \mathrm{~F}_{14}$ can produce a complex arrangement of species that can be extensively cross-linked, making it a prime candidate for polymerization. Fluorochemical functionalization is initiated through the bombardment of unsaturated carbon-carbon bonds by neutral and ionic species (PES membranes) and hydrogen abstraction followed by reaction with fluorine radical species (nylon membranes). The corresponding liquid repellency behavior of perfluorohexane plasma treated PES and nylon membranes is indicated by the surface roughness (porosity and rigidity) observed in SEM images (Fig. 3). A generalized reaction pathway in which perfluorohexane monomers undergo chain-growth polymerization is presented in Eqs. 4-5.

$$
\begin{aligned}
& e+\mathrm{M} \rightarrow \cdot \mathrm{X} \\
& \cdot \mathrm{X}+\mathrm{M} \rightarrow \mathrm{X}-\mathrm{M} .
\end{aligned}
$$

Note: $\mathrm{X}$ represents a fragmented free radical species.

\section{Tetrafluoromethane plasma treatment of polyethersulfone and nylon membranes}

The current work evaluates the dissociation of tetrafluoromethane as a plasma process gas and the subsequent interaction of reactive species with hydrophilic PES and nylon polymer membrane surfaces. When the electron energy exceeds the ionization potential, dissociative ionization will produce various fragments and species. Although tetrafluoromethane possesses a relatively high ionization potential $(17.8 \mathrm{eV})$, it was selected as a process gas due to its fluorine/carbon $(\mathrm{F} / \mathrm{C})$ ratio, which corresponds with the ability to produce an overabundance of excited fluorine species in the plasma state (Kiser and Hobrock 1965; Reed 1955). Surfeit fluorine radicals can bind onto the surface of saturated and unsaturated hydrocarbons through hydrogen abstraction and double bond addition pathways, respectively (Fig. 4) (Hopkins and Badyal 1995). In addition to fluorine radicals, $\mathrm{CF}_{\mathrm{x}}$ (where $\mathrm{x}=1,2$ or 3 ) radicals can graft onto the surface of polymer membranes through similar mechanisms.

Several pore sizes of nylon and PES were treated with $\mathrm{CF}_{4}$ plasmas. The structure and composition of treated and untreated membranes were characterized using SEMEDS. SEM images of the top and bottom surfaces of nylon 

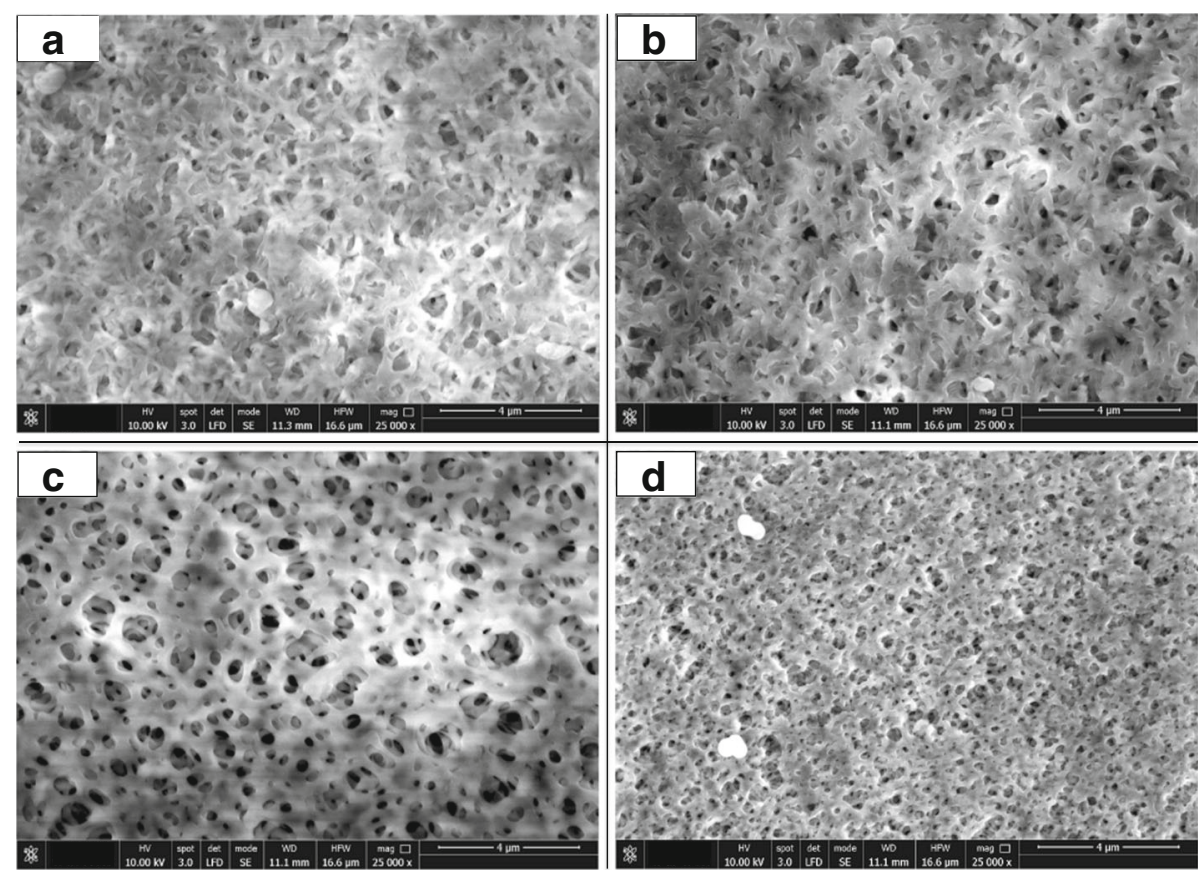

Fig. 3 SEM images at 25,000x of (a) untreated nylon membranes, (b) perfluorohexane plasma treatment of nylon membranes, (c) untreated PES membranes and (d) perfluorohexane plasma treated PES membranes

and PES membranes can be seen in Figs. 5 and 6. Untreated nylon (Fig. 5a-b) membranes present morphology similar at both surfaces. Untreated PES (Fig. 6a-b) membranes illustrate a different morphology on the top and bottom surface. The effectiveness of the $\mathrm{CF}_{4}$ plasma treatment to modify the only exposed surface (top) of nylon and PES membranes is shown in Figs. $5 c-d$ and $6 c-d$, respectively. The bottom surfaces of treated nylon (Fig. 5d) and PES (Fig. 6d) membranes are equivalent to that of their untreated counterparts (Fig. $5 \mathrm{~b}$ and $6 \mathrm{~b}$, respectfully).
Images of treated nylon and PES membranes indicate an increased number of pores, but of reduced diameter following plasma treatment, which is in agreement with the modification mechanism of plasma ablation (Figs. 5a vs. c and 6a vs. c). Plasma ablation occurs at the outermost surface of the polymer membrane and emanates from the disruption of weak covalent $\mathrm{C}-\mathrm{H}$ bonds by energetic electrons and ions. Coinciding with ablation, surface activation of nylon and PES membranes is also evident, as emphasized by the relative increase of fluorine (Table 3).

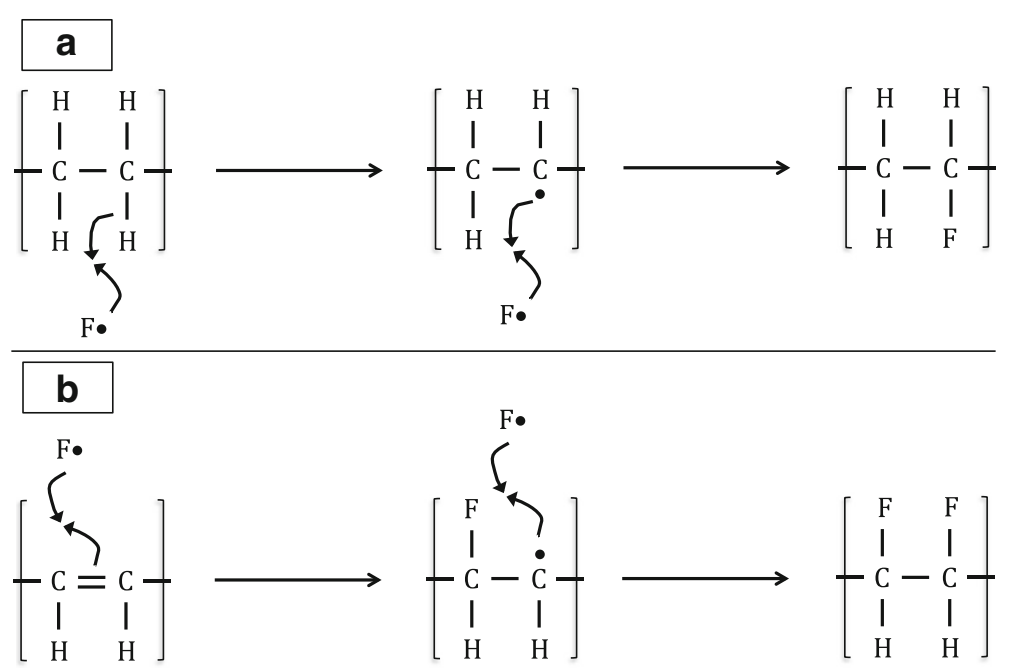

Fig. 4 Surface fluorination suggested pathways for (a) saturated and (b) unsaturated hydrocarbons 

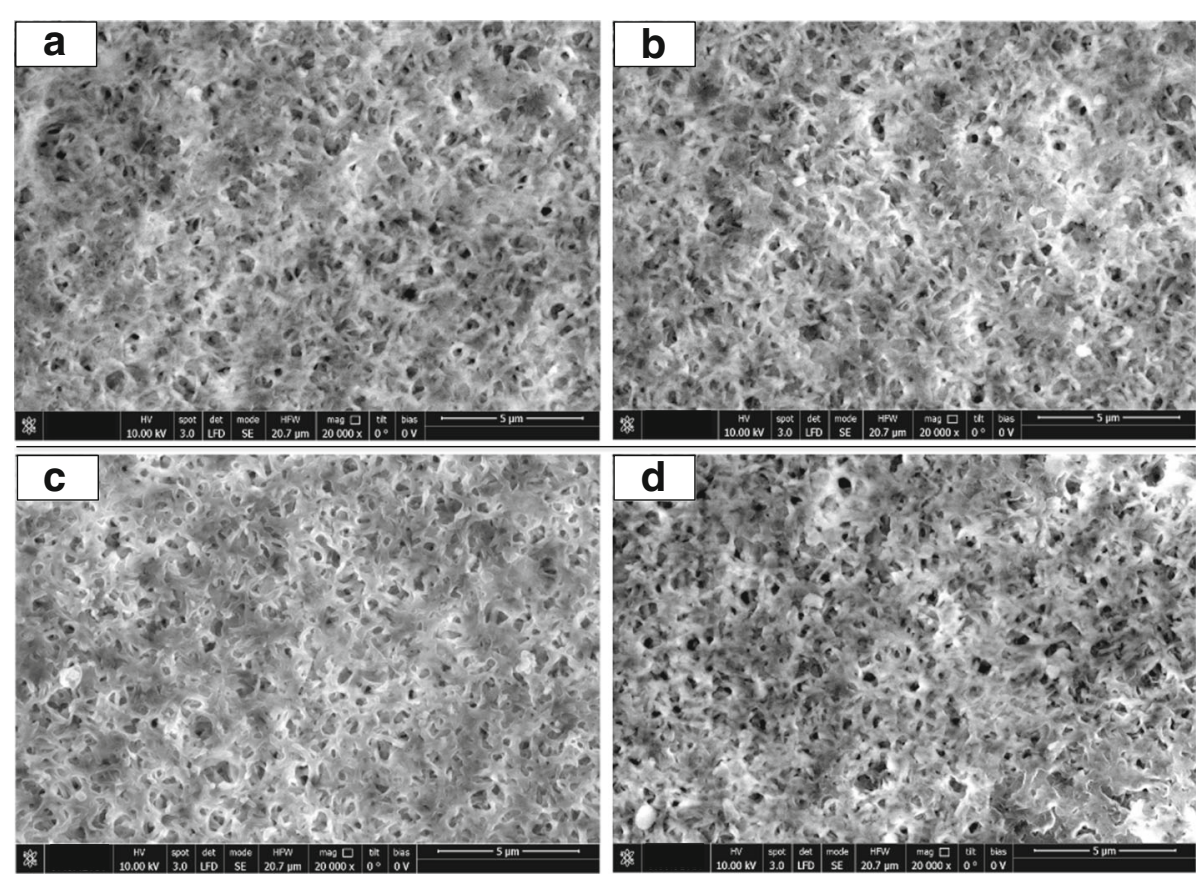

Fig. 5 SEM images at 20,000x of (a) top surface of untreated nylon membranes, (b) bottom surface of untreated nylon membranes, (c) top surface of CF4 plasma treated nylon membranes, (d) bottom surface of CF4 plasma treated nylon membranes
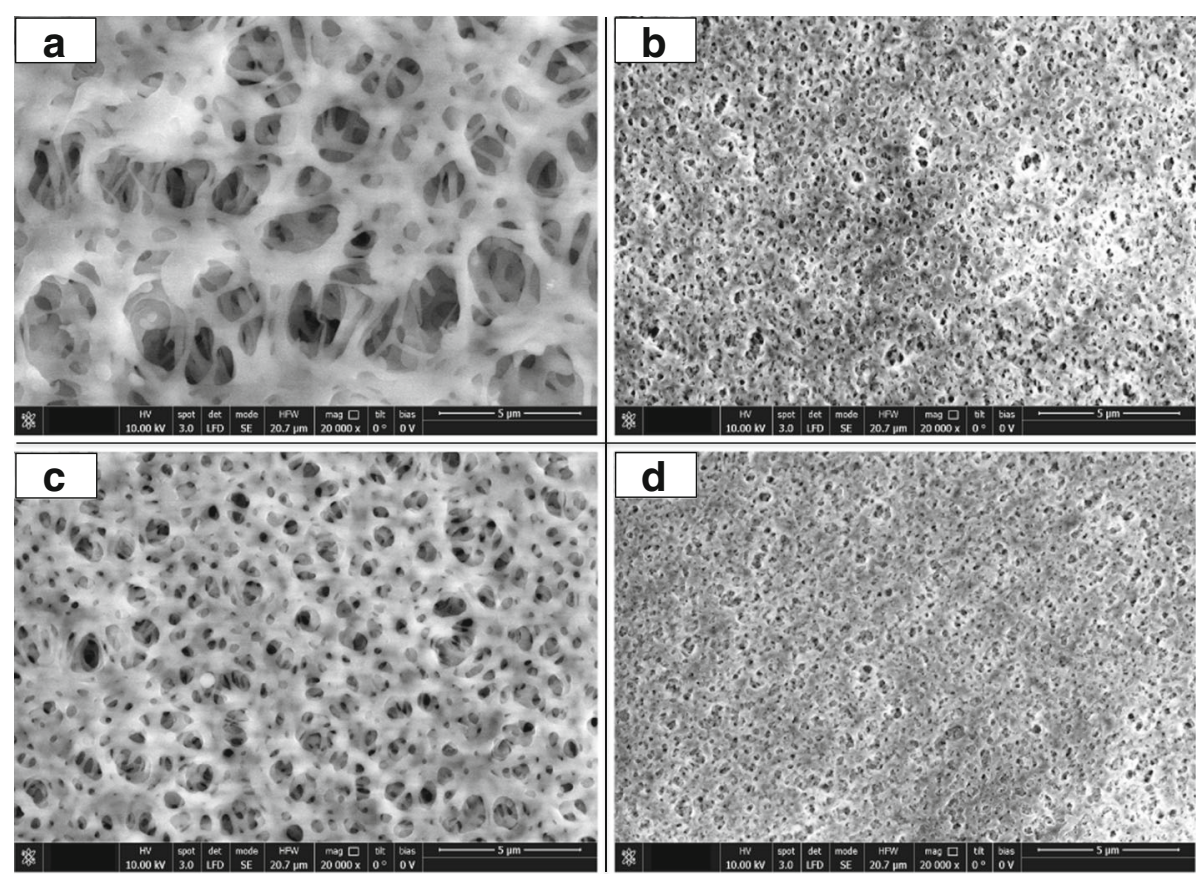

Fig. 6 SEM images at 20,000x of (a) top surface of untreated PES membranes, (b) bottom surface of untreated PES membranes, (c) top surface of CF4 plasma treated PES membranes, (d) bottom surface of CF4 plasma treated PES membranes 
Table 3 Surface chemical composition and atomic ratio of change of Nylon and PES modified by $\mathrm{CF}_{4}$ plasma treatment $(n=1)$

\begin{tabular}{|c|c|c|c|c|c|c|c|c|c|c|}
\hline & \multirow[b]{2}{*}{ Sample } & \multicolumn{9}{|c|}{ Elemental ratio (\%) } \\
\hline & & $C$ & $\mathrm{~N}$ & $\mathrm{O}$ & S & $\mathrm{F}$ & $\mathrm{N} / \mathrm{C}$ & $\mathrm{O} / \mathrm{C}$ & $S / C$ & $\mathrm{~F} / \mathrm{C}$ \\
\hline \multirow[t]{6}{*}{ EDS } & PES Theoretical & 75 & - & 19 & 6 & 0 & - & 0.25 & 0.08 & 0.00 \\
\hline & PES Unprocessed & 80 & - & 15 & 5 & 0 & - & 0.19 & 0.06 & 0.00 \\
\hline & PES $\mathrm{CF}_{4}$ Treated & 78 & - & 15 & 5 & 2 & - & 0.19 & 0.06 & 0.03 \\
\hline & Nylon Theoretical & 75 & 12.5 & 12.5 & - & 0 & 0.16 & 0.16 & - & 0.00 \\
\hline & Nylon Unprocessed & 79 & 10 & 11 & - & 0 & 0.12 & 0.14 & - & 0.00 \\
\hline & Nylon $\mathrm{CF}_{4}$ Treated & 75 & 9 & 11 & - & 5 & 0.12 & 0.15 & - & 0.07 \\
\hline \multirow[t]{6}{*}{ XPS } & PES Theoretical & 75 & - & 19 & 6 & 0 & - & 0.25 & 0.08 & 0.00 \\
\hline & PES Unprocessed & 79 & - & 18 & 4 & 0 & - & 0.25 & 0.04 & 0.00 \\
\hline & PES $\mathrm{CF}_{4}$ Treated & 57 & - & 14 & 2 & 27 & - & 0.25 & 0.04 & 0.48 \\
\hline & Nylon Theoretical & 75 & 12.5 & 12.5 & - & 0 & 0.16 & 0.16 & - & 0.00 \\
\hline & Nylon Unprocessed & 75 & 12 & 13 & - & 0 & 0.16 & 0.17 & - & 0.00 \\
\hline & Nylon $\mathrm{CF}_{4}$ Treated & 43 & 5 & 7 & - & 45 & 0.11 & 0.15 & - & 1.10 \\
\hline
\end{tabular}

Table 3 summarizes the elemental modifications on treated nylon and PES membranes.

Composition changes on the surface of nylon and PES membranes after $\mathrm{CF}_{4}$ plasma treatment were evaluated using EDS and XPS. Compared to EDS, XPS offers more accurate quantitative analysis of surface structures as well as chemical bonding information. As shown in Table 3, EDS results demonstrate that prior to $\mathrm{CF}_{4}$ plasma treatment, the initial elemental $\mathrm{C}: \mathrm{N}: \mathrm{O}$ and $\mathrm{C}: \mathrm{S}: \mathrm{O}$ ratios for nylon and PES membranes respectively were 79:10:11 and 80:5:15. Similarly, XPS results indicate that prior to $\mathrm{CF}_{4}$ plasma treatment, the initial elemental $\mathrm{C}: \mathrm{N}: \mathrm{O}$ and $\mathrm{C}: \mathrm{S}: \mathrm{O}$ ratios for nylon and PES membranes respectively were 75:12:13 and 79:4:18. Elemental ratios of untreated membranes are similar, which indicates the accuracy of fitting. Atomic percentages acquired from both techniques suggest that preceding the $\mathrm{CF}_{4}$ plasma treatment the most abundant element for each membrane type was carbon. Following $\mathrm{CF}_{4}$ plasma treatment, the most copious element for PES membranes remained carbon; however, EDS and XPS analysis indicated a significant increase in fluorine content. Following $\mathrm{CF}_{4}$ plasma treatment, the most abundant element for nylon membranes was fluorine.

Using EDS analysis, the ratio of $F / C$ increased from $(0.00 \rightarrow 0.06)$ and $(0.00 \rightarrow 0.03)$ from untreated to treated nylon and PES membranes respectively. Using $\mathrm{XPS}$ analysis, the ratio of $\mathrm{F} / \mathrm{C}$ increased from $(0.00 \rightarrow$ $1.10)$ and $(0.00 \rightarrow 0.48)$ from untreated to treated nylon and PES membranes respectively. A larger percentage of fluorine depicted by XPS analysis relative to bulk EDS analysis indicates that most of the fluorine is confined to the surface of the membrane. Furthermore, the $\mathrm{x}$-ray penetration depth is considerably small using the XPS technique; thus analysis only observes the top few nanometers of the polymer membranes. During EDS analysis the size of the interactive space increases with the acceleration voltage. Considering the applied acceleration voltage, it is likely EDS analysis penetrates further than the surface of the membrane and represents the bulk properties of the material. An increase in the F/C ratio advocates a deposition or activation of fluorinated species on the surface of the membrane.

Mechanistically, it is suggested that the reactive species likely present as a result of $\mathrm{CF}_{4}$ dissociation are $\mathrm{CF}$, $\mathrm{CF}_{2}, \mathrm{CF}_{3}$ radicals and $\mathrm{F}$ atoms in addition to other ions (Fig. 7, Eqs. 6-10) (Wei et al. 2012; Bae et al. 2001; Henniker Plasma 2016). XPS spectrum suggests that the formation of $\mathrm{CF}_{2}-\mathrm{CF}_{2}, \mathrm{CF}$ and $\mathrm{CF}_{3}$ bonds at the surface of each polymer membrane lead to an enriched fluorine percentage (Fig. 8). An extended treatment time of $30 \mathrm{~min}$ revealed a significant increase in fluorine content; however, the 30-min treatment time appeared to negatively alter the physical properties of the membrane making it fragile and discolored. The enlarged fluorine percentage is described by the plasma modification mechanism of activation, by which hydrogen is substituted with fluorine and various fluorocarbon species. Fluorination of nylon and PES membranes by substitution of hydrogen atoms with fluorine is an energetically favorable process in which HF is a byproduct (Strobel et al. 1985; Flamm et al. 2012; Hopkins and Badyal 1994; Inagaki et al. 1991). In addition to the notion of fluorocarbon chains, cross-linking is also as a potential mechanism as a result of addition reactions to a polymer benzene ring. Concomitant with morphology observations of an increased number of pores in treated membranes, the exchange of hydrogen with fluorine at the surface of the nylon and PES membranes also results in a more rigid structure. Increased rigidity is an 


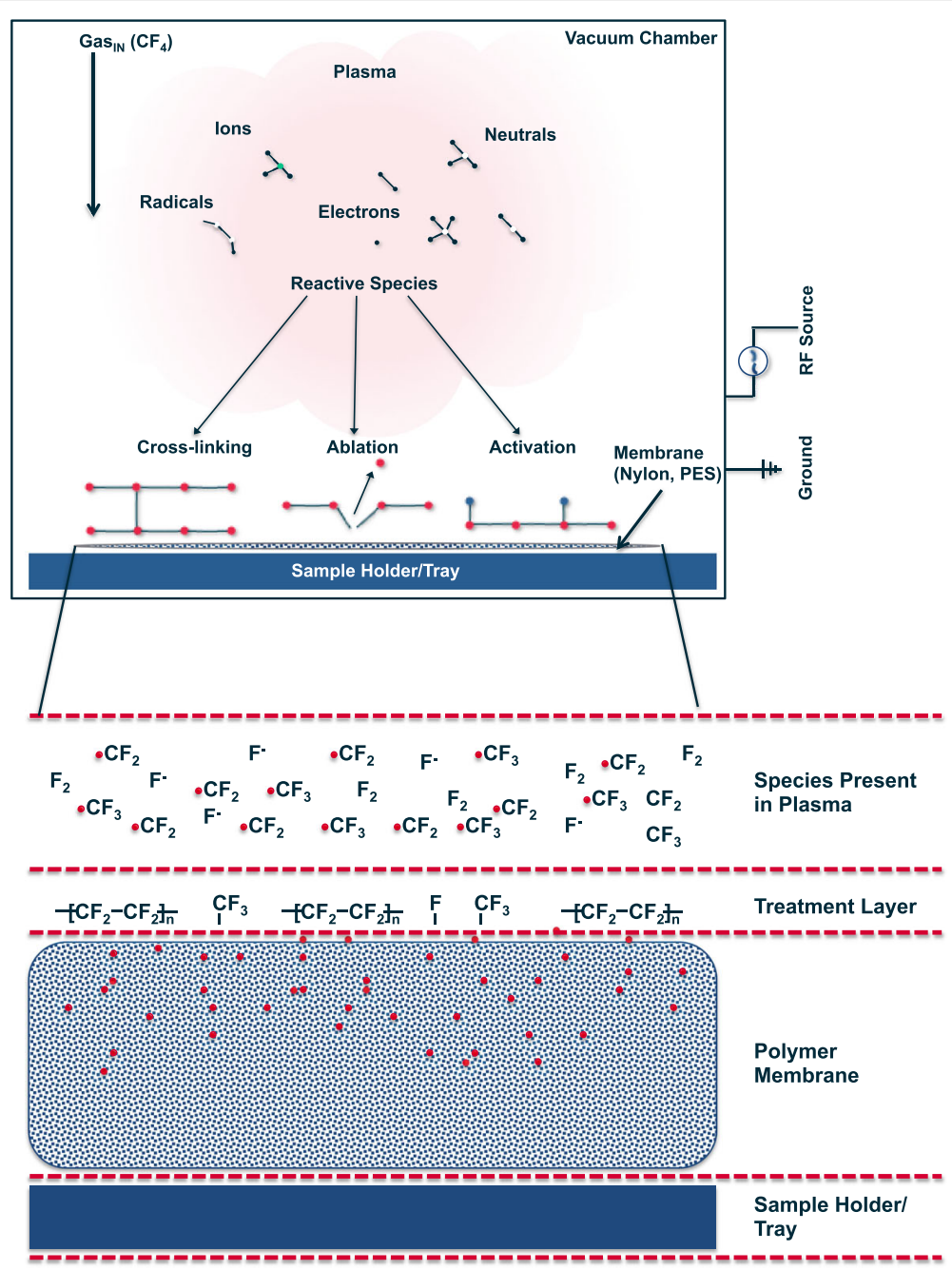

Fig. 7 Schematic illustration of CF4 plasma treatment on nylon and PES membranes adapted from references (Wei et al. 2012; Hopkins and Badyal 1996)

outcome of the rotational and translation hindrance due to the larger atomic size of fluorine compared to hydrogen (Hopkins and Badyal 1996). The plasma modifications describing enhanced rigidness and porosity are therefore a combination of activation and ablation. Results from SEM-EDS and XPS data support the hypothesis that $\mathrm{CF}_{4}$ plasma treatment of nylon and PES membranes leads to the formation of fluorinated layer at the surface of the membrane, which affects the morphology (rigidness) and hydrophobicity (Teflon like C-F bonds).

$$
\begin{aligned}
& e+\mathrm{CF}_{4} \rightarrow e+\mathrm{CF}_{3}+\mathrm{F} \\
& e+\mathrm{CF}_{4} \rightarrow e+\mathrm{CF}_{2}+2 \mathrm{~F} \\
& e+\mathrm{CF}_{3} \rightarrow e+\mathrm{CF}_{2}+\mathrm{F} \\
& e+\mathrm{CF}_{2} \rightarrow e+\mathrm{CF}+\mathrm{F}
\end{aligned}
$$

$$
e+\mathrm{CF} \rightarrow e+\mathrm{C}+\mathrm{F}
$$

Key characteristics embodying a biomimetic polymer membrane are a 1 - upon hydration in an aqueous environment an unstirred water layer is formed and $2-$ a hydrophobic surface mimics the lipophilic features of the intestinal epithelial cells. SEM, EDS and XPS data confirm the effectiveness of $\mathrm{CF}_{4}$ plasma treatments to create a hydrophobic surface on hydrophilic nylon and PES membranes. Further quantification on the change at the modified hydrophobic surface of the membranes is done using water contact angle analysis. The water contact angle (CA) is primarily affected by, hydrophilicity, roughness and porosity (Cassie and Baxter 1944). The increase in water contact angles further supports this notion for nylon and PES membranes. Results demonstrate a significant rise in the water contact angle (nylon: $0^{\circ}$ to $135^{\circ}, \mathrm{PES}: 0^{\circ}$ 

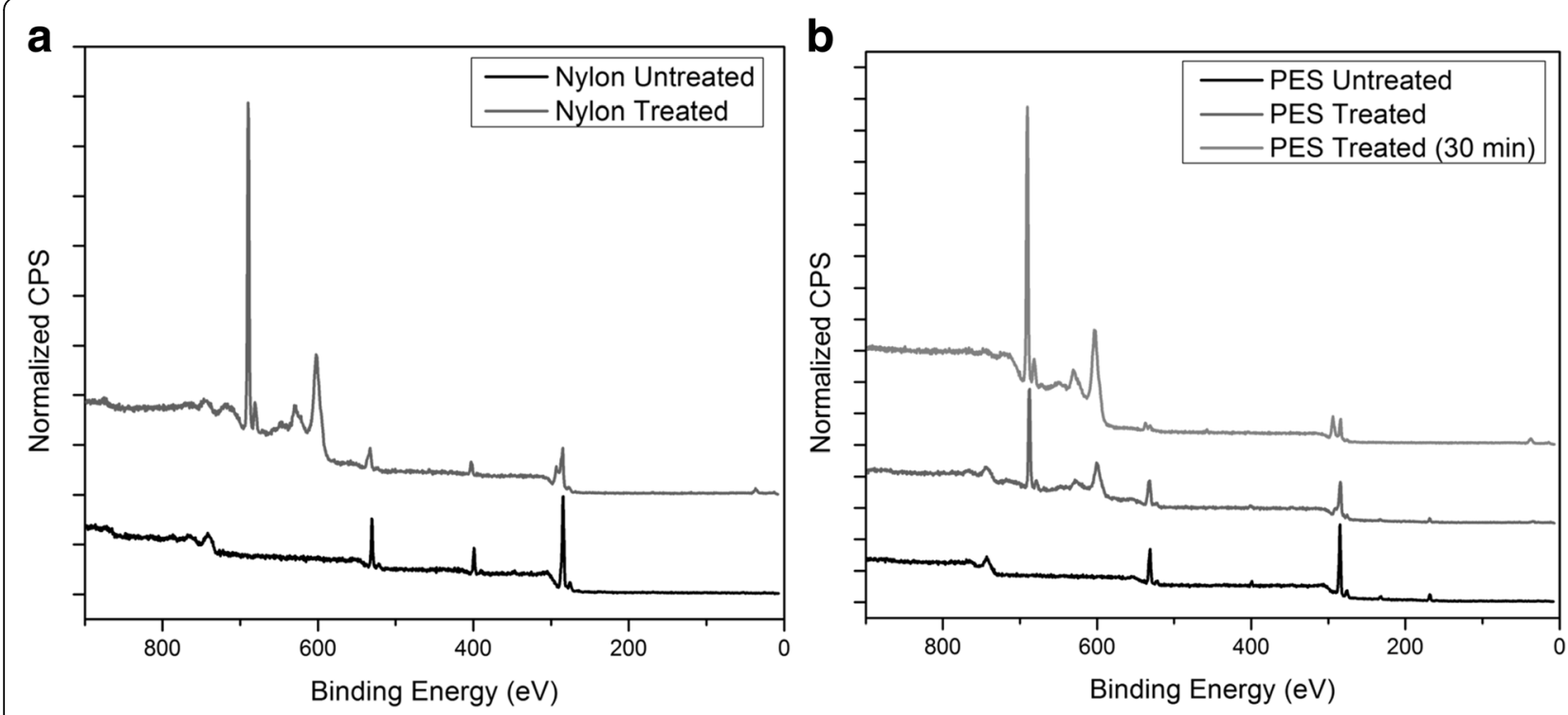

Fig. 8 XPS core level spectra for untreated and CF4 plasma treated (a) nylon and (b) PES membranes

to $125^{\circ}$ as well as $40^{\circ}$ to $125^{\circ}$ ) at the surface of treated membranes (Table 1). The contact angle of PES membranes was dependent upon the surface analyzed. The water contact angles also verify that the $\mathrm{CF}_{4}$ plasma treatment only affects the surface exposed to the plasma for nylon and PES membranes. Plasma treatments result in a membrane that retains the original hydrophilic properties of nylon (CA: $0^{\circ}$ to $0^{\circ}$ ) and PES (CA: $0^{\circ}$ to $0^{\circ}$, as well as $40^{\circ}$ to $40^{\circ}$ ) on one surface while introducing hydrophobic properties on the other.

\section{Application of $\mathrm{CF}_{4}$ plasma treated biomimetic membranes in membrane-permeation dissolution studies}

This research was designed to construct a biomimetic membrane that could be employed to predict the performance of amorphous solid dispersions using a membranepermeation dissolution method; which thereby, provides rationale and support during formulation development. In a supplemental study, a detailed comparison of the $\mathrm{CF}_{4}$ plasma treated polymer membranes and porcine intestines is presented by Puppolo et al. (Puppolo et al. 2017). This work demonstrates the biomimetic nature of the plasma treated polymer membranes by evaluating multiple statistical relationships, including Bland-Altman analysis and correlation coefficients (Puppolo et al. 2017). It should be noted that of the four membrane modifications investigated $\left(\mathrm{H}_{2} \mathrm{O}, \mathrm{DCM}, \mathrm{C}_{6} \mathrm{~F}_{14}, \mathrm{CF}_{4}\right)$, only $\mathrm{CF}_{4}$ plasma treated membranes provided reproducible dissolution performance. Following a comprehensive assessment of the dissolution performance (area under the dissolution curve and flux values) for $\mathrm{CF}_{4}$ plasma treated nylon and PES membranes relative to porcine intestines, PES membranes with a pore size of $0.1 \mu \mathrm{m}$ were employed for a comparison of hot melt extruded and spray dried Felodipine solid dispersions (Puppolo et al. 2017). The supplemental work presented by Puppolo et al. illustrates the utility of $\mathrm{CF}_{4}$ plasma treated membranes in a membrane-permeation dissolution experiment (Puppolo et al. 2017).

\section{Conclusions}

Industry accepted in vitro dissolution methodologies expend numerous resources to emulate in vivo conditions. To that point, existing membrane-permeation dissolution techniques utilize membranes that are expensive to manufacture and may be unrepresentative of the intestinal epithelium as they exhibit thick unstirred aqueous layers, large molecular weight cut-offs and limited stability in buffered environments. Plasma modification of polymer membranes is a viable solution to membrane limitations. In the current work, synthetic biomimetic polymer membranes were explored as an option to circumvent undesirable membrane. Conducive to the success of plasma modified microporous membranes are advantageous factors such as cost, lifetime, chemical/pH compatibility and control over the depth of the unstirred aqueous layer. A few shortcomings regarding plasma treated polymer membranes are treatment homogeneity, treatment depth and lack of efflux transporters. As shown in low temperature hydrophilic and hydrophobic plasma treatment studies, tailored polymer membrane modifications depicted asymmetric surfaces and possessed amphipathic properties. The type of membrane modification proved dependent upon the selected process gas and/or solvent.

Water vapor plasma treatment of hydrophobic polypropylene membranes demonstrated increased membrane aqueous wettability; however, were limited by treatment 
stability compared to hydrophobic treatments. Dichloromethane and perfluorohexane plasma treatments of hydrophilic PES and nylon membranes engendered chlorinated and fluorinated hydrophobic surfaces respectively; however, such treatments suffered from reproducibility challenges. Due to a fluorine/carbon ratio $(>3)$, results from $\mathrm{CF}_{4}$ plasma treatments indicated surface fluorination of PES and nylon membranes occurred. Observations suggest fluorination as a more effective and less destructive treatment technique. Dissolution testing was used to compare treated membranes with porcine intestines (Puppolo et al. 2017). Dissolution results indicated that $\mathrm{CF}_{4}$ plasma treated PES membranes with a pore size of $0.1 \mu \mathrm{m}$ exhibited similar transport properties when compared to porcine intestines.

\section{Abbreviations \\ $\mathrm{C}_{6} \mathrm{~F}_{14}$ : Perfluorohexane; $\mathrm{CA}$ : Water contact angle; $\mathrm{CF}_{4}$ : Tetrafluoromethane; DCM: Dichloromethane; GIT: Gastrointestinal tract; $\mathrm{H}_{2} \mathrm{O}$ : Water; PAMPA: Parallel artificial membrane permeability assay; PES: Polyethersulfone; PP: Polypropylene; SEM-EDS: Scanning electron microscopy energy dispersive $x$-ray spectroscopy; XPS: X-ray photoelectron spectroscopy}

\section{Acknowledgements}

The authors would like to gratefully acknowledge the financial support of Hovione LLC. The authors would also like to thank Dr. Dmitriy Dikin for his assistance in performing SEM-EDS analyses.

\section{Authors' contributions}

TD carried out the plasma treatments, participated in membrane surface analysis and assisted in drafting the manuscript. EC carried out XPS experiments and data analysis. DS participated in the drafting of the manuscript. SJV participated in the design of the plasma treatment study and assisted with the data analysis of surface characterization experiments. BW participated in the design of the study, performed the water contact analyses and coordinated the draft of the manuscript. JH and MP conceived of the study, participated in the design and coordination of the study and helped to draft the manuscript. All authors read and approved the final manuscript.

\section{Competing interests}

The authors declare that they have no competing interests.

\section{Publisher's Note}

Springer Nature remains neutral with regard to jurisdictional claims in published maps and institutional affiliations.

\section{Author details \\ ${ }^{1}$ Hovione LLC, 40 Lake Drive, East Windsor, NJ 08520, USA. ${ }^{2}$ Department of Chemistry, Temple University, 1901 North 13th Street, Philadelphia, PA 19122, USA. ${ }^{3}$ Patheon, part of Thermo Fischer Scientific, 4215 Premier Drive, High Point, NC 27265, USA.}

Received: 9 February 2017 Accepted: 2 October 2017

Published online: 24 October 2017

\section{References}

Artursson P, Knight SD (2015) Breaking the intestinal barrier to deliver drugs. Science 347(6223):716-717

Artursson P, Palm K, Luthman K (2001) Caco-2 monolayers in experimental and theoretical predictions of drug transport. Adv Drug Deliv Rev 46(1):27-43

Azarmi S, Roa W, Löbenberg R (2007) Current perspectives in dissolution testing of conventional and novel dosage forms. Int J Pharm 328(1):12-21

Bae B, Chun B-H, Kim D (2001) Surface characterization of microporous polypropylene membranes modified by plasma treatment. Polymer 42(18): 7879-7885
Baker RW (2002) Future directions of membrane gas separation technology. Ind Eng Chem Res 41(6):1393-1411

Booth J, Cunge G, Chabert P, Sadeghi N (1999) CFx radical production and loss in a CF4 reactive ion etching plasma: fluorine rich conditions. J Appl Phys 85: 3097-3107

Bryjak M, Gancarz I, Poźniak G, Tylus W (2002) Modification of polysulfone membranes 4. Ammonia plasma treatment. Eur Polym J 38(4):717-726

Cassie A, Baxter S (1944) Wettability of porous surfaces. Trans Faraday Soc 40:546-551

Cheng Q (2011) Polymer surface modification for bioengineering applications. University of California, Berkley

Coburn J, Winters HF (1979) Plasma etching-a discussion of mechanisms. J Vac Sci Technol 16(2):391-403

Desmet T, Morent R, Geyter ND, Leys C, Schacht E, Dubruel P (2009) Nonthermal plasma technology as a versatile strategy for polymeric biomaterials surface modification: a review. Biomacromolecules 10(9):2351-2378

Fakhru'I-Razi A, Pendashteh A, Abdullah LC, Biak DRA, Madaeni SS, Abidin ZZ (2009) Review of technologies for oil and gas produced water treatment. J Hazard Mater 170(2):530-551

Flamm DL, Auciello O (2012) Plasma deposition, treatment, and etching of polymers: the treatment and etching of polymers. Elsevier.

Gomathi N, Sureshkumar A, Neogi S (2008) RF plasma-treated polymers for biomedical applications. Curr Sci 1478-1486. https://www.researchgate.net/ publication/228681199

Helander HF, Fändriks L (2014) Surface area of the digestive tract-revisited. Scand J Gastroenterol 49(6):681-689

Henniker Plasma - Plasma Treatment. 2016

Ho JY, Matsuura T, Santerre JP (2000) The effect of fluorinated surface modifying macromolecules on the surface morphology of polyethersulfone membranes. J Biomater Sci Polym Ed 11(10):1085-1104

Hopkins J, Badyal J (1994) Plasma modification of poly (ether sulfone). Macromolecules 27(19):5498-5503

Hopkins J, Badyal J (1995) Nonequilibrium glow discharge fluorination of polymer surfaces. J Phys Chem 99(12):4261-4264

Hopkins J, Badyal J (1996) CF4 plasma treatment of asymmetric polysulfone membranes. Langmuir 12(15):3666-3670

Hubert J, Poleunis C, Delcorte A, Laha P, Bossert J, Lambeets S et al (2013) Plasma polymerization of $\mathrm{C} 4 \mathrm{Cl} 6$ and $\mathrm{C} 2 \mathrm{H} 2 \mathrm{Cl} 4$ at atmospheric pressure. Polymer 54(16):4085-4092

Inagaki N, Tasaka S, Mori K (1991) Hydrophobic polymer films plasmapolymerized from CF4/hydrocarbon and hexafluroacetone/hydrocarbon mixtures. J Appl Polym Sci 43(3):581-588

Kansy M, Senner F, Gubernator K (1998) Physicochemical high throughput screening: parallel artificial membrane permeation assay in the description of passive absorption processes. J Med Chem 41(7):1007-1010

Kim K, Lee K, Cho K, Park C (2002) Surface modification of polysulfone ultrafiltration membrane by oxygen plasma treatment. J Membr Sci 199(1):135-145

Kiser RW, Hobrock DL (1965) The ionization potential of carbon Tetrafluoride. J Am Chem Soc 87(4):922-923

Krause B, Storr M, Ertl T, Buck R, Hildwein H, Deppisch R et al (2003) Polymeric membranes for medical applications. Chem Ing Tech 75(11):1725-1732

Liston E, Martinu L, Wertheimer M (1994) Plasma surface modification of polymers for improved adhesion: a critical review. Plasma Surf Modif Polym: Relevance Adhes:3-39

Liston EM (1989) Plasma treatment for improved bonding: a review. J Adhes 30(1-4):199-218

Macheras P, Karalis V, Valsami G (2013) Keeping a critical eye on the science and the regulation of oral drug absorption: a review. J Pharm Sci 102(9):3018-3036

Maisel K, Ensign L, Reddy M, Cone R, Hanes J (2015) Effect of surface chemistry on nanoparticle interaction with gastrointestinal mucus and distribution in the gastrointestinal tract following oral and rectal administration in the mouse. J Control Release 197:48-57

Martinez H, Flores O, Campillo B, Gomez A, Salazar-Flores L, Poveda J (2012) $\mathrm{CH} 2 \mathrm{Cl} 2$ thin film formation on low-pressure DC plasma discharge. Radiat Eff Defects Solids 167(8):583-593

Obeso CG, Sousa MP, Song W, Rodriguez-Pérez MA, Bhushan B, Mano JF (2013) Modification of paper using polyhydroxybutyrate to obtain biomimetic superhydrophobic substrates. Colloids Surf A Physicochem Eng Asp 416:51-55

Penn L, Wang H (1994) Chemical modification of polymer surfaces: a review. Polym Adv Technol 5(12):809-817 
Porter CJ, Trevaskis NL, Charman WN (2007) Lipids and lipid-based formulations: optimizing the oral delivery of lipophilic drugs. Nat Rev Drug Discov 6(3):231-248

Puppolo MM et al (2017) Biomimetic dissolution: a tool to predict amorphous solid dispersion performance. AAPS PharmSciTech 1-13. doi:10.1208/s12249017-0783-4

Reed T III (1955) The ionization potential and the polarizability of molecules. J Phys Chem 59(5):428-432

Robeson LM (1999) Polymer membranes for gas separation. Curr Opinion Solid State Mater Sci 4(6):549-552

Rowland M (1972) Influence of route of administration on drug availability. J Pharm Sci 61(1):70-74

Ruell J (2003) Membrane-based drug assays. Modern Drug Disc 6:28-30

Selli E, Riccardi C, Massafra MR, Marcandalli B (2001) Surface modifications of silk by cold SF6 plasma treatment. Macromol Chem Phys 202(9): 1672-1678

Shannon MA, Bohn PW, Elimelech M, Georgiadis JG, Marinas BJ, Mayes AM (2008) Science and technology for water purification in the coming decades. Nature 452(7185):301-310

Strobel M, Corn S, Lyons CS, Korba GA (1985) Surface modification of polypropylene with CF4, CF3H, CF3Cl, and CF3Br plasmas. J Polym Sci: Polym Chem Ed 23(4):1125-1135

Strobel M, Lyons CS, Mittal K. Plasma surface modification of polymers: relevance to adhesion: Vsp; 1994

Upadhyay D, Bhat N (2003) Surface modification and characterization of dichloromethane plasma treated polypropylene film. Plasmas Polym 8(4): 237-257

van de Waterbeemd $\mathrm{H}$ (2000) Intestinal permeability: prediction from theory. Drugs Pharm Sci 106:31-50

Wagner C, Davis L, Zeller M, Taylor J, Raymond R, Gale L (1981) Empirical atomic sensitivity factors for quantitative analysis by electron spectroscopy for chemical analysis. Surf Interface Anal 3(5):211-225

Wavhal DS, Fisher ER (2005) Modification of polysulfone ultrafiltration membranes by CO 2 plasma treatment. Desalination 172(2):189-205

Wei X, Zhao B, Li X-M, Wang Z, He B-Q, He T et al (2012) CF 4 plasma surface modification of asymmetric hydrophilic polyethersulfone membranes for direct contact membrane distillation. J Membr Sci 407:164-175

Yasuda H (1978) Glow discharge polymerization. Thin Film Processes 361-396. doi:10.1002/pol.1981.230160104

York P. Design of dosage forms 2013

Zhao C, Xue J, Ran F, Sun S (2013) Modification of polyethersulfone membranesa review of methods. Prog Mater Sci 58(1):76-150

\section{Submit your manuscript to a SpringerOpen ${ }^{\circ}$ journal and benefit from:}

- Convenient online submission

- Rigorous peer review

- Open access: articles freely available online

- High visibility within the field

- Retaining the copyright to your article

Submit your next manuscript at $\gg$ springeropen.com 